\title{
Psychological Impact of COVID-19 Pandemic on Mental Health of General Population of Islamabad, Pakistan
}

\author{
Muhammad Afzal ${ }^{1}$, Hameed Mumtaz Durrani ${ }^{2}$, Muhammad Imran Sohail ${ }^{3}$ \\ ${ }^{1}$ Biostatistician, Research and Publication, Shaheed Zulfiqar Ali Bhutto Medical University, Islamabad Pakistan \\ ${ }^{2}$ Assistant Professor, Department of Community Medicine, Shifa College of Medicine, Islamabad Pakistan \\ ${ }^{3}$ Deputy Director Surveillance, Ministry of Health WHO, Islamabad Pakistan
}

\begin{abstract}
A B S TRACT
Background: Most of the ongoing research on COVID-19 is related to development of an effective vaccine and treatment for this illness, while psychological impact on mental health remains underexplored. The objective of this study was to determine the psychological impact of COVID-19 pandemic on the mental health of the general population of Islamabad. Material and Methods: This cross-sectional study was conducted among the general population of Islamabad, during a period of two months from 15th May to 15th July 2020. A total of 278 participants were given a structured questionnaire based on Hospital Anxiety and Depression Scale (HADS) scoring system to calculate depression and anxiety. The possible scores for depression and anxiety ranged 0-21. A cut off value of 8 and above was used to identify anxiety and depression with higher scores indicating increased severity.

Results: The mean age of the participants was $33.42 \pm 9.67$ years and 148 (53.2\%) were males. Among these , 238 ( $85.6 \%)$ were residents of urban area, and 167 (60.1\%) were married. Most of the participants were graduate 102 (36.7\%). Thirty-six (12.9\%) participants had a known patient of COVID-19 in their family or friends. Most of the participants 196 (70.5\%) had no comorbidity. The mean anxiety score was noted to be $6.47 \pm 5.51$ and mean depression score was 6.65 \pm 4.17. Presence of any comorbidity showed a highly significant association with anxiety and depression score $(P<.01)$. Conclusions: There was no significant psychological impact of COVID-19 on mental health of the population of Islamabad. However, people with comorbidities showed a significantly raised anxiety and depression status on the HADS score.

Key words: Anxiety, COVID-19, Depression, General population, Mental health

$\begin{array}{lll}\text { Authors' Contribution: } & \text { Correspondence: } & \text { Article info: } \\ { }^{1} \text { Conception; Literature research; } & \text { Muhammad Afzal } & \text { Received: August 28, 2020 } \\ \text { manuscript design and drafting; }{ }^{2,3} \text { Critical } & \text { Email:afzal419@gmail.com } & \text { Accepted: November 15, 2020 } \\ \text { analysis and manuscript review; Data } & & \\ \text { analysis; Manuscript Editing. } & & \end{array}$
\end{abstract}

Cite this article. Afzal M, Durrani MH, Sohail MI. Psychological Impact of COVID-19 Pandemic on Mental Health of General Population of Islamabad, Pakistan. J Islamabad Med Dental Coll. 2020; 9(4): 256-261. Doi: 10.35787/jimdc.v9i4.592

Funding Source: Nil
Conflict of Interest: Nil

\section{Introduction}

COVID-19 is a global public health challenge now a days. It has emerged as a pandemic with growing number of cases worldwide. Due to rapid spread, it has become a critical challenge for health systems world over, which are failing in prevention, identification and proper management of this infection. $^{1}$ 
Various countries have minimized the spread of COVID-19 infection through lock down and social distancing policies. However, in many developing countries like Pakistan people are not taking these measures seriously. ${ }^{2}$ Since the mode of spread is mainly droplet infection through person-to-person contact, so the compliance with social distancing interventions is vital to the control of spread. Many studies have reported a significant reduction in COVID-19 spread by strictly following social distancing measures. ${ }^{3,4}$

This infectious disease has many physical as well as mental health implications. ${ }^{5}$ People around the world have many fears and worries associated with it. People start fearing from falling sick or dying and helplessness. ${ }^{6}$ These feelings worsen due to closure of business and schools compounding the situation. Thus, it is not only due to lack of effective treatment or unavailability of vaccine but also due to adverse socioeconomic consequences linked with it. People are affected by unemployment and shortage of necessary commodities as a result of lockdowns or quarantine. These kinds of psychological impacts have also been observed in non-infected community during previous pandemics like SARS outbreak. ${ }^{9}$ All these factors may have adverse impact on mental health, requiring special attention of health practitioners and researchers around the globe. ${ }^{7,8}$

The studies conducted during previous pandemics showed that some factors are significantly associated with stress, anxiety. The factors include older age, female gender, people having higher education level, history of contact with positive cases and individuals having symptoms of disease. The information on impact of COVID-19 on mental health of general population is lacking in our country. This information is specially required during a pandemic of such unparalleled magnitude..$^{9,10}$

The research work on examining the psychological impact of COVID-19 on the general population of Pakistan is very limited. Therefore, this study was planned to investigate the psychological impact and mental health in the general population during the COVID-19 outbreak. This may assist government agencies and healthcare professionals in safeguarding the psychological wellbeing of our community in the face of COVID-19 outbreak.

\section{Material and Methods}

This cross-sectional study was conducted in Islamabad, Pakistan over a period of two months from $15^{\text {th }}$ May to $15^{\text {th }}$ July, 2020. Throughout this period a smart or full lock down was enforced by Government of Pakistan in the country and the number of new and confirmed cases were at a peak.

A total of 278 participants were selected for this study by non-probability consecutive sampling technique from the general population of Islamabad. Both males and females, between 18 to 65 years of age, were enrolled for the study. Sample size was calculated with the help of WHO sample size calculator using confidence level of 95\%, anticipated population proportion (rate of depression among general population) of $23.6 \%$ and absolute precision of $5 \% .{ }^{11}$ This study was approved by the Ethics Review Board of Shaheed Zulfiqar Ali Bhutto Medical University dated June 4, 2020.

A questionnaire with a statement regarding informed consent, was distributed amongst the participants for documenting demographic information (i.e., age, gender and marital status) in addition to questions related to anxiety and depression, which were part of HADS scoring. HADS consists of 14 questions, each of which is scored 03. Anxiety and depression are evaluated with seven questions each. The lowest possible scores for depression and anxiety are 0 , and the highest possible scores are 21. A cut off value of 8 and above was used with higher scores indicating increased severity of anxiety or depression. 
All the collected data was entered in Statistical Package for Social Sciences (SPSS version 21.0) for analysis. Quantitative data was presented in the form of mean and SD and qualitative data was presented with the help of frequency and percentages. Independent sample t-test was applied to compare HADS score on the basis of age and gender. One-way ANOVA test was applied to compare mean values of HADS score on the basis of education levels, profession, and comorbid diseases. Chi-square test was applied to compare qualitative variables like gender, marital status, education level, profession, income loss and comorbid disease. $P$ value $\leq .05$ was taken as statistically significant.

\section{Results}

A total of 278 participants were enrolled in this study. The mean age of the study participants was $33.42 \pm 9.67$ years and the majority were males 148 (53.2\%). Most of the participants 238 (85.6\%) were residents of urban area, and 167 (60.1\%) were married. Maximum number of the participants were graduates ( $n=102 ; 36.7 \%$ ) followed by with Higher Secondary School Certification (Matriculation) only ( $n=93 ; 33.5 \%)$. Majority of the participants were running their own business ( $n=99 ; 35.6 \%)$ followed by government employees $(n=51 ; 18.3 \%)$. At the time of inclusion in the study, 84 (30.2\%) respondents were jobless, mostly due to lockdown (Table I).

The results of our study showed that 81 (29.1\%) participants had anxiety symptoms and 119 (42.8\%) respondents appeared to have positive symptoms of depression on the basis of HADS scoring system. The mean anxiety score was $6.47 \pm 5.51$ and the mean depression score was $6.65 \pm 4.17$ as shown in table II.

\begin{tabular}{|c|c|c|}
\hline Characteristics & Frequency & Percentage \\
\hline \multicolumn{3}{|c|}{ Age of the participant (years) } \\
\hline Mean \pm SD & \multicolumn{2}{|c|}{$33.42 \pm 9.67$} \\
\hline \multicolumn{3}{|c|}{ Gender of the participant } \\
\hline Male & 148 & 53.2 \\
\hline Female & 130 & 46.8 \\
\hline \multicolumn{3}{|c|}{ Place of residence } \\
\hline Urban & 238 & 85.6 \\
\hline Rural & 40 & 14.4 \\
\hline \multicolumn{3}{|l|}{ Marital Status } \\
\hline Married & 167 & 60.1 \\
\hline Single & 111 & 39.9 \\
\hline \multicolumn{3}{|l|}{ Education Level } \\
\hline Illiterate & 18 & 6.5 \\
\hline Matric & 93 & 33.5 \\
\hline Graduation & 102 & 36.7 \\
\hline Post-graduation & 65 & 23.4 \\
\hline \multicolumn{3}{|l|}{ Profession } \\
\hline Business & 99 & 35.6 \\
\hline Private Job & 44 & 15.8 \\
\hline Govt. Job & 51 & 18.3 \\
\hline Jobless & 84 & 30.2 \\
\hline
\end{tabular}

The comparison of anxiety and depression score on the basis of gender, marital status, education level, profession and income loss during pandemic showed that no variable had any significant relationship with anxiety or depression score $(P>$ .05). However, presence of comorbidities like diabetes mellitus, hypertension or both had a highly significant association with anxiety and depression score $(P<.01)$ (Table III).

Discussion

Epidemics and pandemics have extreme influences on psychological wellbeing of a given population and the behaviors of the community are influenced by the fear and anxiety of being affected. ${ }^{12}$ During an infectious pandemic like the COVID-19, various preventive measures are adopted to reduce the spread of disease. These measures include selfisolation, social distancing and lockdowns, although 


\begin{tabular}{|c|c|c|}
\hline \multicolumn{3}{|c|}{ Table II: Descriptive statistics of different variables } \\
\hline Characteristics & Frequency & Percentage \\
\hline \multicolumn{3}{|l|}{ Income lost due to Pandemic } \\
\hline Yes & 131 & 47.1 \\
\hline No & 147 & 52.9 \\
\hline \multicolumn{3}{|c|}{ Known patient of COVID-19 in family and friends } \\
\hline Yes & 36 & 12.9 \\
\hline No & 242 & 87.1 \\
\hline \multicolumn{3}{|c|}{ History of contact with COVID-19 patient in the last week } \\
\hline Yes & 48 & 17.3 \\
\hline No & 230 & 82.7 \\
\hline \multicolumn{3}{|l|}{ Comorbidities } \\
\hline None & 196 & 70.5 \\
\hline Diabetes Mellitus & 39 & 14 \\
\hline HTN & 24 & 8.6 \\
\hline DM and HTN & 19 & 6.8 \\
\hline \multicolumn{3}{|c|}{ Anxiety Status on the basis of HADS score } \\
\hline No Anxiety Symptoms $(<8)$ & 197 & 70.9 \\
\hline Anxiety Symptoms $(\geq 8)$ & 81 & 29.1 \\
\hline \multicolumn{3}{|c|}{ Depression Status on the basis of HADS score } \\
\hline No Depression Symptoms $(<8)$ & 159 & 57.2 \\
\hline Depression Symptoms $(\geq 8)$ & 119 & 42.8 \\
\hline
\end{tabular}

\begin{tabular}{|c|c|c|c|c|c|c|}
\hline \multicolumn{7}{|c|}{ Table III: Association of Anxiety and Depression Score with different variables } \\
\hline \multirow{2}{*}{ Characteristics } & \multicolumn{2}{|c|}{ Anxiety Score } & \multirow{2}{*}{$P$-value* } & \multicolumn{2}{|c|}{ Depression Score } & \multirow{2}{*}{$P$-value } \\
\hline & Mean & SD & & Mean & SD & \\
\hline \multicolumn{7}{|c|}{ Gender of the participant } \\
\hline Male & 6.40 & 5.368 & \multirow{2}{*}{.806} & 6.71 & 4.208 & \multirow{2}{*}{.804} \\
\hline Female & 6.56 & 5.684 & & 6.58 & 4.150 & \\
\hline \multicolumn{7}{|l|}{ Marital Status } \\
\hline Married & 6.63 & 5.65 & \multirow{2}{*}{.554} & 6.71 & 4.209 & \multirow{2}{*}{.786} \\
\hline Single & 6.23 & 5.305 & & 6.57 & 4.138 & \\
\hline \multicolumn{7}{|l|}{ Education level } \\
\hline Illiterate & 5.06 & 4.721 & \multirow{4}{*}{.239} & 6.94 & 4.556 & \multirow{4}{*}{.989} \\
\hline Matric & 5.95 & 5.378 & & 6.58 & 4.079 & \\
\hline Graduation & 7.27 & 5.880 & & 6.68 & 4.191 & \\
\hline Post-graduation & 6.37 & 5.222 & & 6.63 & 4.267 & \\
\hline \multicolumn{7}{|l|}{ Profession } \\
\hline Business & 7.01 & 5.618 & \multirow{4}{*}{.310} & 6.32 & 4.522 & \multirow{4}{*}{.420} \\
\hline Private Job & 5.30 & 5.083 & & 6.14 & 3.968 & \\
\hline Govt. Job & 5.98 & 5.210 & & 6.82 & 3.871 & \\
\hline Jobless & 6.76 & 5.741 & & 7.20 & 4.026 & \\
\hline \multicolumn{7}{|c|}{ Income lost due to Pandemic } \\
\hline Yes & 6.92 & 5.559 & \multirow{2}{*}{.200} & 6.73 & 4.188 & \multirow{2}{*}{.780} \\
\hline No & 6.07 & 5.451 & & 6.59 & 4.174 & \\
\hline \multicolumn{7}{|l|}{ Comorbidities } \\
\hline None & 4.87 & 4.200 & \multirow{4}{*}{.001} & 5.84 & 3.889 & \multirow{4}{*}{.001} \\
\hline Diabetes Mellitus & 10.28 & 5.987 & & 9.05 & 4.365 & \\
\hline Hypertension & 7.29 & 6.203 & & 7.04 & 4.048 & \\
\hline DM and HTN & 14.16 & 5.336 & & 9.63 & 3.715 & \\
\hline
\end{tabular}


at the same time number of patients with the disease and death rates increases significantly. Mental health of the society gets adversely affected by all these factors. The psychological effects of the pandemic may be expected in terms of high depression and anxiety levels. ${ }^{13,14}$

In our study, although $47.1 \%$ participants reported loss of income due to pandemic, but there was no statistically significant association with anxiety or depression. This is quite contrary to the findings of Holmes et al. in their comparative study between Israel and US respondents. They found a significant association between losing income due to COVID-19 and anxiety and depression symptoms. ${ }^{15}$ There may be a chance that the difference in findings is due to difference in sample size as we had a limited sample size of 278 participant and Holmes at al. compared two independent studies with a collective sample of around 6500 participants. We cannot ascertain that the use of different scales (HADS in our study and GAD-7 in other) for measuring anxiety and depression could have been responsible for different findings because both scales are termed equally reliable for the purpose. However, we believe that the magnitude of the disaster and sensitivity to its fatalness might have been one of the causes of difference in results.

According to Cao and colleagues, the chance of anxiety and depression increased three times $(O R=$ 3.00) if the participant had a positive case of infection in family or friends. ${ }^{16}$ In our study, we had a limited number of people (12.9\%) having a patient of COVID-19 in relatives and friends and this was not significantly associated with the symptoms of anxiety and depression. We think that this may be due to the limited spread of the disease in Islamabad at the time of data collection (May to July, 2020).

An important finding of our study was that the presence of comorbidities like diabetes mellitus and hypertension is the most significant risk factor of developing anxiety and depression. These observations are in-line with results of Ozdin and coworkers. ${ }^{11}$ They reported similar findings in their study using the HADS. In addition, they found that being females and residents of urban areas was also significantly associated with symptoms of anxiety and depression. In our study however, the mean scores of males and female participants of urban and rural areas was within the normal range of HADS.

Psychological aspect of pandemic has equal importance in terms of proper management as the physical health. ${ }^{17}$ To minimize the effect of COVID19 pandemic on mental health of the general population, attention should be given to the vulnerable groups like unemployed individuals and people with chronic comorbidities, like diabetes mellitus and hypertension.

This study was conducted on the population of a single city; therefore, the results cannot be generalized. This became a major limitation of our study. More studies on a larger scale should be conducted to ascertain the exact impact of COVID 19 pandemic on mental health of the general population of Pakistan.

\section{Conclusion}

There was no significant psychological impact of COVID-19 on mental health of the population of Islamabad. However, people with comorbidities showed a significantly raised anxiety and depression status on the HADS score.

\section{References}

1. Legido-Quigley $\mathrm{H}$, Asgari $\mathrm{N}$, Teo $\mathrm{YY}$, Leung GM, Oshitani H, Fukuda K, et al. Are high-performing health systems resilient against the COVID-19 epidemic? Lancet. 2020; 395(10227): 848-50. Doi: 10.1016/S0140-6736(20)30551-1.

2. Shoaib M, Abdullah F. Risk Reduction of COVID-19 Pandemic in Pakistan. Soc Work Public Health. 2020; 35(7): 557-68. Doi: 10.1080/19371918.2020.1806172

3. Ahmed F, Zviedrite N, Uzicanin A. Effectiveness of workplace social distancing measures in reducing 
influenza transmission: A systematic review. BMC Public Health. 2018; 18(1): 1-13. Doi: 10.1186/s12889-018-5446-1

4. Roy D, Tripathy S, Kar SK, Sharma N, Verma SK, Kaushal V. Study of knowledge, attitude, anxiety \& perceived mental healthcare need in Indian population during COVID-19 pandemic. Asian J Psychiatr. 2020; 51: $102083 . \quad$ Doi: 10.1016/j.ajp.2020.102083

5. Galea S, Merchant RM, Lurie N. The Mental Health Consequences of COVID-19 and Physical Distancing: The Need for Prevention and Early Intervention. JAMA Intern Med. 2020; 180(6): 817-8. Doi: 10.1001/jamainternmed.2020.1562.

6. Van Bortel T. Psychosocial effect of an Ebola outbreak at individual, community and international levels. Bull World Health Organ. 2016; 94(3): 210-4. Doi: 10.2471/BLT.15.158543

7. Nicola M, Alsafi Z, Sohrabi C, Kerwan A, Al-Jabir A, losifidis $C$, et al. The socio-economic implications of the coronavirus pandemic (COVID-19): A review. Int J Surg. 2020; 78: 185-93. Doi: 10.1016/j.ijsu.2020.04.018

8. Holmes EA, O'Connor RC, Perry VH, Tracey I, Wessely $S$, Arseneault $L$, et al. Multidisciplinary research priorities for the COVID-19 pandemic: a call for action for mental health science. Lancet Psychiatr. 2020; 7(6): 547-60. Doi: 10.1016/S2215-0366(20)30168-1

9. Xiong J, Lipsitz O, Nasri F, Lui LMW, Gill H, Phan L, et al. Impact of COVID-19 pandemic on mental health in the general population: A systematic review. J Affect Disord. 2020; 277: 55-64. Doi: 10.1016/j.jad.2020.08.001

10. Wang C, Pan R, Wan X, Tan Y, Xu L, Ho CS, et al. Immediate Psychological Responses and Associated Factors during the Initial Stage of the 2019 Coronavirus Disease (COVID-19) Epidemic among the General Population in China. Int J Environ Res Public
Health. 2020; 17(5): $1729 . \quad$ Doi: 10.3390/ijerph17051729

11. Ozdin S, Bayrak Ozdin S. Levels and predictors of anxiety, depression and health anxiety during COVID19 pandemic in Turkish society: The importance of gender. Int J Soc Psychiatry. 2020; 66(5): 504-11. Doi: $10.1177 / 0020764020927051$

12. Banerjee D. The COVID-19 outbreak: Crucial role the psychiatrists can play. Asian J Psychiatr. 2020; 50: 102014. Doi: 10.1016/j.ajp.2020.102014

13. Shi L, Lu ZA, Que JY, Huang XL, Liu L, Ran MS, et al. Prevalence of and risk factors associated with mental health symptoms among the general population in china during the coronavirus disease 2019 pandemic. JAMA. 2020; 3(7): e2014053. Doi: 10.1001/jamanetworkopen. 2020.14053

14. Asmundson GJG, Taylor S. How health anxiety influences responses to viral outbreaks like COVID19: What all decision-makers, health authorities, and health care professionals need to know. J Anxiety Disord. 2020; 71: $102211 . \quad$ Doi: 10.1016/j.janxdis.2020.102211

15. Hertz-Palmor N, Moore TM, Gothelf D, DiDomenico GE, Dekel I, Greenberg DM, Brown LA, Matalon N, Visoki E, White LK, Himes MH, Lifshitz-Schwartz M, Gross R, Gur RC, Gur RE, Pessach IM, Barzilay R. Association among income loss, financial strain and depressive symptoms during COVID-19: evidence from two longitudinal studies. medRxiv [Preprint]. 2020 Sep 18: 2020.09.15.20195339. Doi: 10.1101/2020.09.15.20195339.

16. Cao W, Fang Z, Hou G, Han M, Xu X, Dong J, Zheng J. The psychological impact of the COVID-19 epidemic on college students in China. Psychiatry Res. 2020; 287: 112934. Doi: 10.1016/j.psychres.2020.112934.

17. Betsch C, Wieler LH, Habersaat K; COSMO group. Monitoring behavioral insights related to COVID-19. Lancet. 2020; 395(10232): 1255-6. Doi: 10.1016/S0140-6736(20)30729-7 